\title{
Development of a tool for calculating early internal doses in the Fukushima Daiichi nuclear power plant accident based on atmospheric dispersion simulation
}

\author{
Osamu Kurihara ${ }^{1, *}$, Eunjoo Kim ${ }^{1}$, Naoaki Kunishima ${ }^{1,2}$, Kotaro Tani $^{1}$, Tetsuo Ishikawa ${ }^{3}$, Kazuo Furuyama ${ }^{1}$, \\ Shozo Hashimoto ${ }^{1}$ and Makoto Akashi ${ }^{1}$ \\ ${ }^{1}$ National Institutes for Quantum and Radiological Sciences and Technology, National Institute of Radiological Sciences, \\ 4-9-1 Anagawa Inage-ku, Chiba city, Chiba, Japan \\ ${ }^{2}$ Self-Defense Forces Central Hospital, 1-2-24 Ikejiri, Setagaya-ku, Tokyo, Japan \\ ${ }^{3}$ Fukushima Medical University, 1-Hikarigaoka, Fukushima city, Fukushima, Japan
}

\begin{abstract}
A tool was developed to facilitate the calculation of the early internal doses to residents involved in the Fukushima Nuclear Disaster based on atmospheric transport and dispersion model (ATDM) simulations performed using Worldwide version of System for Prediction of Environmental Emergency Information 2nd version (WSPEEDI-II) together with personal behavior data containing the history of the whereabouts of individul's after the accident. The tool generates hourly-averaged air concentration data for the simulation grids nearest to an individual's whereabouts using WSPEEDI-II datasets for the subsequent calculation of internal doses due to inhalation. This paper presents an overview of the developed tool and provides tentative comparisons between direct measurement-based and ATDM-based results regarding the internal doses received by 421 persons from whom personal behavior data available.
\end{abstract}

\section{Introduction}

A huge amounts of radionuclides was released into the environment as a consequence of the accident at the Tokyo Electric Power Company's (TEPCO's) Fukushima Daiichi Nuclear Power Plant (FDNPP) in 2011 [1]. The Japanese Government ordered residents living near the FDNPP to evacuate shortly after the accident in order to minimize their radiation exposure. It was reported that most of the residents evacuated in accordance with the evacuation orders [2].

Needless to say, it is of great importance to evaluate the levels of radiation exposure in the populations living in the radiologically affected areas. Much effort has been made on this task up to the present; however, there still remain many difficulties in estimating the early internal dose due to the intake of short-lived radionuclides represented by iodine-131 $\left({ }^{131} \mathrm{I}\right)$, a significant contributor of internal thyroid doses in particular for small children. Neither human nor environmental measurements could be adequately performed shortly after the accident. According to the published research [3-6], only around 1,300 human measurements were performed within the first two month after the accident. Extensive direct (in vivo) measurements using whole-body counters (WBCs) were started in late June, 2011[7, 8]; however, ${ }^{131}$ I could not have been detected at this point of time.

One of the possible solutions to estimating the early internal dose is to make use of atmospheric transport and dispersion model (ATDM) simulations of the radionuclides. The authors have reported the feasibility of this method based on the results of the Worldwide version of System for Prediction of Environmental Emergency Dose Information 2nd version (WSPEEDIII) developed by the Japan Atomic Energy Agency (JAEA) [9]. In the study, the early internal doses calculated from the time-series ground level air concentration maps $\left({ }^{131} \mathrm{I},{ }^{137} \mathrm{Cs}\right)$ produced by WSPEEDIII were compared to those obtained from direct measurement results on the assumption that the individuals remained outdoors at all time at representative places or behaved in accordance with a representative evacuation pattern. As a result, it was found that the former doses were several times higher than the 90th percentile values of the latter doses. This discrepancy was supposed to be minimized by taking into account actual personal behaviors after the accident.

Afterwards, personal behavior data became partially available to the authors through the permission of research ethics committees of the National Institute of Radiological Sciences (NIRS) and Fukushima Medical University (FMU). These data were produced based on a self-administrative questionnaire about each individual's whereabouts for the first four months after the accident and have been used for calculating the external doses to residents of Fukushima Prefecture in the first four months after the accident [10]. The authors were provided with the personal behavior data of those for whom direct measurement results were available. The present paper describes the development of a tool for facilitating internal dose calculations using the results of WSPEEDI-II and shows tentative comparisons between the direct-measurement-based and ATDM-based internal

*Corresponding author: kurihara.osamu@qst.go.jp 
doses to 421 persons for whom personal behavior data were available.

\section{Materials and methods}

\subsection{ATDM simulations}

The developed tool used datasets from the time-series ground-level air concentration maps produced using WSPEEDI-II (Table 1). The original simulations that produced these datasets have been described elsewhere $[11,12]$. The results obtained by Terada et al were cited by the United Nations Scientific Committee on the Effect of Atomic Radiation (UNSCEAR) [13], and the findings of Katata et al were obtained by utilizing an updated source term based on newly obtained environmental data and an improved deposition scheme. Each dataset contains hourly-averaged air concentration maps of the radionuclides from March 12 to May 1 (Terada-Regional) or to April 1 (Katata-Regional, Katata-Local), 2011. The physicochemical form of ${ }^{131} \mathrm{I}$ was not considered in the simulations by Terada et al, whereas it was separately calculated for elemental iodine $\left(\mathrm{I}_{2}\right)$, methyl iodine $\left(\mathrm{CH}_{3} \mathrm{I}\right)$ and particulate iodine in the simulations by Katata et al. The calculation domains of each simulation are shown in Figure 1. The nominal spatial resolutions of the regional and local models are 3 $\mathrm{km} \times 3 \mathrm{~km}$ and $1 \mathrm{~km} \times 1 \mathrm{~km}$, respectively.

Table 1. Simulation datasets used in the tool.

\begin{tabular}{|c|c|c|c|}
\hline Dataset & Terada-Regional & Katata-Regional & Katata-Local \\
\hline $\begin{array}{l}\text { Calculation domains } \\
\text { (Covered area) }\end{array}$ & $\begin{array}{c}681 \mathrm{~km} \text { x } 951 \mathrm{~km} \\
\text { (East Japan) }\end{array}$ & $\begin{array}{c}381 \mathrm{~km} \text { x } 561 \mathrm{~km} \\
\text { (East Japan) }\end{array}$ & $\begin{array}{c}187 \mathrm{~km} \times 187 \mathrm{~km} \\
\text { (Fukushima Prefecture) }\end{array}$ \\
\hline Spatial resolution (nominal) & $3 \mathrm{~km} \times 3 \mathrm{~km}$ & $3 \mathrm{~km} \times 3 \mathrm{~km}$ & $1 \mathrm{~km} \times 1 \mathrm{~km}$ \\
\hline Time resolution & \multicolumn{3}{|c|}{$1 \mathrm{~h}$} \\
\hline Period of calculation in 2011 & $\begin{array}{l}\text { from 6:00 on Mar. } 12 \text { to } \\
\text { 0:00 on May. } 1 \text { (JST*) }\end{array}$ & $\begin{array}{l}\text { from 6:00 on Mar. } 12 \text { to } \\
\text { 5:00 on April. } 1 \text { (JST*) }\end{array}$ & $\begin{array}{l}\text { from 6:00 on Mar. } 12 \text { to } \\
\text { 5:00 on April. } 1 \text { (JST*) }\end{array}$ \\
\hline Data size & about $64 \mathrm{~GB}$ & about $14.4 \mathrm{~GB}$ & about $21.6 \mathrm{~GB}$ \\
\hline Radionuclide & ${ }^{131} \mathrm{I},{ }^{137} \mathrm{Cs}$ & \multicolumn{2}{|c|}{${ }^{131} \mathrm{I}$ (particulate, elemental, methyl iodide), ${ }^{132} \mathrm{Te},{ }^{134} \mathrm{Cs},{ }^{137} \mathrm{Cs}$} \\
\hline
\end{tabular}

* Japan Standard Time
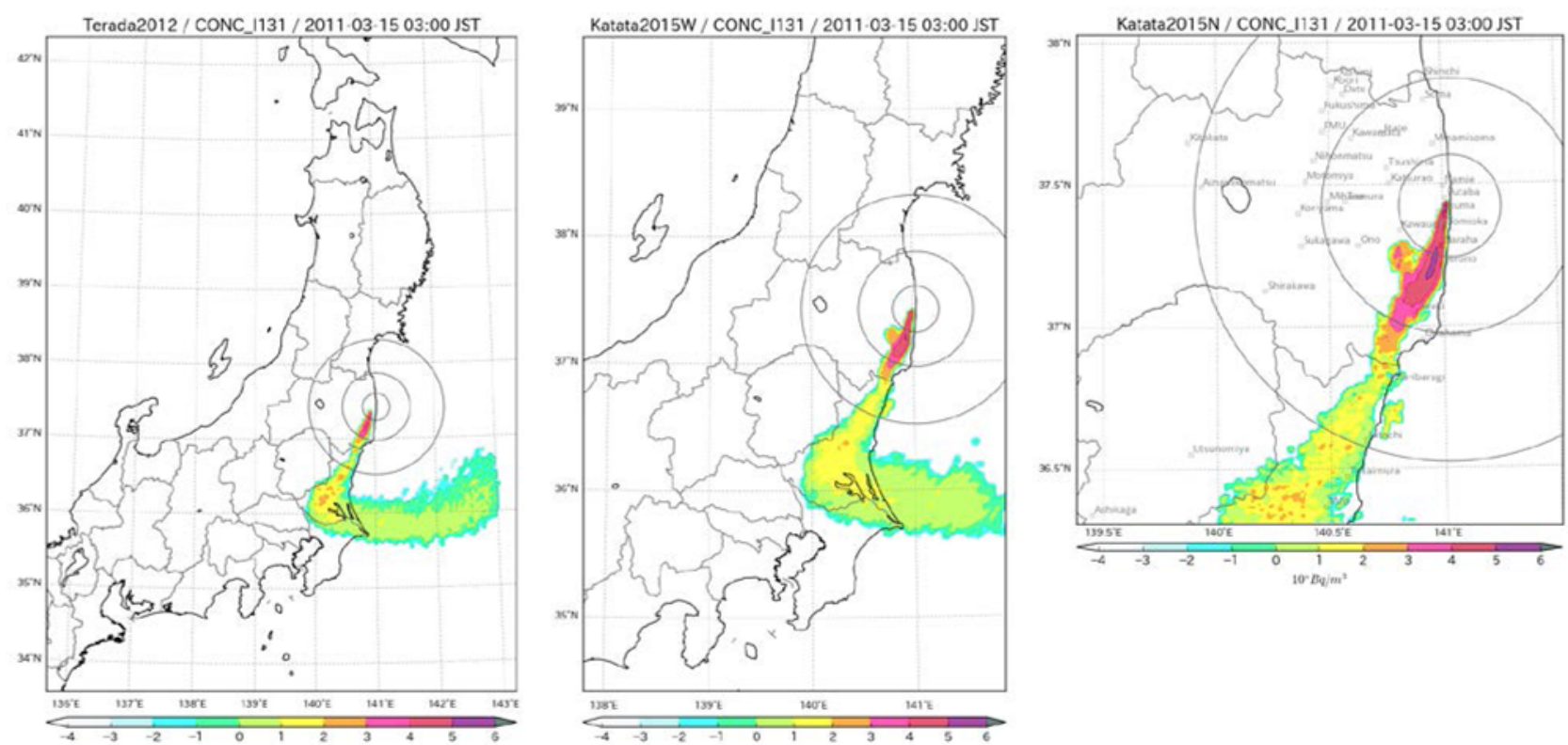

Figure 1. Calculation domains of the datasets used in tool (left: Terada-Regional, middle: Katata-Regional, right: Katata-Local).

\subsection{Personal behaviour data}

The personal behavior data provided include the whereabouts (the place name and its latitude and longitude) and time spent indoors, outdoors or in migration during the first four months after the accident.
All these data were stored in digital files. The data were provided in different formats depending on the period of time (Table 2). The information on the whereabouts was obtained hourly for the first and second periods (March 12 to March 25, 2011), whereas was obtained in terms of daily representative places (mostly one place) where the subject stayed for the last period (March 26 to July 11, 2011). However, complete information is not necessarily 
available because some data were missing. Additionally, the subject's whereabouts during migration from one place to another is basically unknown, which could result in a large uncertainty in the internal dose estimation, in particular for those who migrated over a long distance and for a long period of time.

For this study, the authors received 422 personal behavior data from FMU. These persons comprised 310 of 1,080 subjects (children) of the thyroid exposure screening campaign conducted by the Nuclear Emergency Response Local Headquarters at the end of March, 2011 and 112 of 174 subjects of the pilot survey by means of a WBC at the NIRS during the period between June 27 and July 28, 2011. The internal doses of the 421 persons (one subject of the screening campaign was not identified) were already evaluated using the direct measurement results in the previous studies $[8,14]$ and were compared with those obtained in this study. However, this comparison is rather tentative because the former doses were evaluated assuming a simple intake scenario, namely acute inhalation on March 15 for the subjects of the screening campaign or March 12 for the subjects of the pilot survey. This scenario would somewhat overestimate the internal doses.

Table 2. Formats of personal behavior data.

\begin{tabular}{|c|l|}
\hline Period in 2011 & \multicolumn{1}{c|}{ Data format } \\
\hline Mar. 12 - Mar. 16 & Hourly place data (staying, departure and destination) are written on each column. \\
\hline Mar. 17 - Mar. 25 & $\begin{array}{l}\text { Place data (staying, departure and destination) are written on each row. The time of departure } \\
\text { from the place where the person was present in the morning is calculated from the sum of the } \\
\text { time duration of the migration. }\end{array}$ \\
\hline Later Mar. 26 & Place where the person was present in the morning and visited temporarily. \\
\hline
\end{tabular}

\subsection{Development of the tool}

The tool was designed assuming that it would need to manipulate a huge amount of simulation data (with a number of items per one original simulation dataset being on the giga order) generated by WSPEEDI-II and also possibly additional personal behavior data in the future. From this point of view, a commercial package of database software was not suitable because of the limitated data manipulation that is possible.

The tool has been developed using the $\mathrm{C} \#$ language with the .NET Framework 4.6 (Microsoft Corporation, US) and is operable on personal computers (64 bits) with Windows 7 or later. In this tool, all data used in the analyses were stored in databases that were originally designed to enable traverse access. As a result, users can instantly access the desired information after the data are loaded into the PC memory. The tool operations can be performed by both the Command Prompt in Windows and the Graphic User Interface (GUI). The main tasks of the tool are as follows.

- Interpolation of personal behavior data

As described above, the personal behavior data were provided in the different formats depending on the period of time. To facilitate the subsequent dose calculations, the tool interpolates these data to be arrayed hourly as same as in WSPEEDI-II. The first individual's whereabouts on each day was assigned to every hour of the day during the period on or after March 26, 2011 (Table 2), because of the lack of information on the exact times at which the subjects were engaged in specific behaviors. When data were missing on a certain day, it was assumed that the person continued to stay at the place given last in the personal behavior data.
Extraction of the air concentration data

The tool extracts the air concentration data from the simulation grid (and its surrounding eight grids) nearest the place where the person stayed at a certain time from the datasets of WSPEEDI-II. In the case of a period of migration, the air concentration data were extracted for the place of departure and the destination. The extraction was performed hourly until the end of the simulations using the results of the previous task.

\section{Visualization of the outputs}

The extracted air concentration data can be displayed in multiple graphs as a function of time, which is useful as it allows one to see when the person was most significantly exposed to radioactive plumes. The tool can also create animations of the radioactive plumes of the radionuclide selected and the movement of the persons selected using Google Earth.

\subsection{Internal dose calculations}

The function of the internal dose calculations has not been incorporated in the current version of the tool, but it is easy to perform this function using the extracted air concentration data and a commercial spreadsheet software package such as Microsoft EXCEL. In this study, the internal dose was calculated using the following equation.

$$
D_{i, j}=e_{i, j} \times I_{i, j}=e_{i, j} \times \sum_{k} C_{i, n e a r e s t}\left(t_{k}\right) \cdot b_{j} \cdot F\left(t_{k}\right)
$$

where, suffixes $i, j$ and $k$ denote the radionuclide, the age group and the chronological number of the air concentration map, respectively, $e$ is the dose per unit intake (DPUI) $\left(\mathrm{Sv} \mathrm{Bq}^{-1}\right), C_{\text {nearest }}(t)$ is the hourly averaged air concentration at the time $t$ at the nearest simulation 
grid $\left(\mathrm{Bq} \mathrm{m}^{-3}\right)$ (or is the average of the air concentrations at the place of departure and the destination in the case of migration), $b$ is the ventilation volume per hour $\left(\mathrm{m}^{3}\right)$ and $F$ is the ratio of indoor to outdoor air concentration.

Regarding ${ }^{131} \mathrm{I}$, the internal dose calculations were separately performed for each physicochemical form in the case of the datasets by Katata et al, whereas they were performed using the weighted DPUI of ${ }^{131} \mathrm{I}(60 \%$ of elemental iodine and $40 \%$ of particulate iodine) in the case of the dataset of Terada et al. The composition of the weighted DPUI was determined based on observations at the FDNPP and three JAEA sites in Ibaraki Prefecture (located south of Fukushima Prefecture) [15]. The parameters used in Equation (1) are provided in Table $3[16,17]$

Table 3. Parameters used in internal dose calculations.

\begin{tabular}{|l|c|c|c|c|c|c|}
\hline \multicolumn{1}{|c|}{ Age-group } & infant & $\mathbf{1 - y}$ & $\mathbf{5 - y}$ & $\mathbf{1 0 - y}$ & $\mathbf{1 5 - y}$ & adult \\
\hline Ventilation volume $\left(\mathrm{m}^{3} \mathrm{~d}^{-1}\right)$ & 2.86 & 5.16 & 8.72 & 15.3 & 20.1 & 22.2 \\
\hline Dose coefficient $\left(\mathrm{Sv} \mathrm{Bq}^{-1}\right)$ & & & & & & \\
\hline Effective dose of ${ }^{134} \mathrm{Cs}^{*}$ & $1.1 \mathrm{E}-08$ & $7.3 \mathrm{E}-09$ & $5.2 \mathrm{E}-09$ & $5.3 \mathrm{E}-09$ & $6.3 \mathrm{E}-09$ & $6.6 \mathrm{E}-09$ \\
\hline Effective dose of ${ }^{137} \mathrm{Cs}^{*}$ & $8.8 \mathrm{E}-09$ & $5.4 \mathrm{E}-09$ & $3.6 \mathrm{E}-09$ & $3.7 \mathrm{E}-09$ & $4.4 \mathrm{E}-09$ & $4.6 \mathrm{E}-09$ \\
\hline Thyroid equivalent dose of ${ }^{131} \mathrm{I}$ & & & & & & \\
\hline$\left(\mathrm{CH}_{3} \mathrm{I}\right)$ & $2.6 \mathrm{E}-06$ & $2.5 \mathrm{E}-06$ & $1.5 \mathrm{E}-06$ & $7.4 \mathrm{E}-07$ & $4.8 \mathrm{E}-07$ & $3.1 \mathrm{E}-07$ \\
\hline$\left(\mathrm{I}_{2}\right)$ & $3.3 \mathrm{E}-06$ & $3.2 \mathrm{E}-06$ & $1.9 \mathrm{E}-06$ & $9.5 \mathrm{E}-07$ & $6.2 \mathrm{E}-07$ & $3.9 \mathrm{E}-07$ \\
\hline$($ Particulate $)$ & $1.4 \mathrm{E}-06$ & $1.4 \mathrm{E}-06$ & $7.3 \mathrm{E}-07$ & $3.7 \mathrm{E}-07$ & $2.2 \mathrm{E}-07$ & $1.5 \mathrm{E}-07$ \\
\hline
\end{tabular}

* Type $\mathrm{F}$ compunds

\section{Results and discussion}

\subsection{Overview of the tool}

Figure 2 shows the start-up screen of the tool. The functions of each panel on the screen can be explained as follows. Figure $2 \mathrm{a}$ depicts the time-series of the air concentrations from all the WSPEEDI-II datasets at the gird nearest the latitude and longitude that a user designates. The air concentrations at the surrounding eight grids can be also displayed on sub panels. Figure $2 \mathrm{~b}$ and Figure 2c depict graphs similar to those in the previous figure, but for the person(s) selected. The former can compare all the WSPEEDI-II datasets in terms of one selected person and the latter can compare multiple persons in terms of one selected dataset. The air concentrations displayed on these panels are those extracted based on the personal behavior data. Whether the average of the air concentrations at the place of departure and the destination during migration is used or not can also be chosen on these panels. Figure $2 \mathrm{~d}$ is a screenshot of Google Earth with the simulation data and the marks of the places where the selected persons stayed. Figure $2 \mathrm{e}$ is the screen for controlling the animation on Google Earth. The numbers of subjects who correspond to the search criteria (i.e., subject group, age group, gender, municipality, date) are also displayed in the same panel.

\subsection{Examples of output from the tool}

The time-series of the air concentrations at the places where the persons stay (Figures $2 b$ and $2 c$ ) correspond to the relative intake amount rate via inhalation, which is one of the modifiers of the internal dose evaluated from direct measurements. Figure 3 demonstrates the comparison of the ${ }^{137} \mathrm{Cs}$ air concentration between Terada-Regional (Figure 3a) and Katata-Regional (Figure $3 \mathrm{~b}$ ) for the 112 subjects of the pilot survey. As shown, the largest intake for most of the subjects occured on different days in the two simulations: March 15 for Terada-Regional and March 12 for KatataRegional. About a half of the 112 subjects are from Namie town. Their personal behavior data suggested that most of them evacuated within a few days after the accident. On the other hand, this period is of great importance in determining the early internal dose because of the abundance of short-lived radionuclides other than ${ }^{131} \mathrm{I}$. The dose contributions of ${ }^{132} \mathrm{Te}\left(\mathrm{T}_{1 / 2}: 3.2\right.$ d)- ${ }^{132} \mathrm{I}\left(\mathrm{T}_{1 / 2}: 2.3 \mathrm{~h}\right)$ and ${ }^{133} \mathrm{I}\left(\mathrm{T}_{1 / 2}: 20.8 \mathrm{~h}\right)$ were estimated to be as great as $30-40 \%$ of the internal thyroid dose from ${ }^{131} \mathrm{I}$ in the case of inhalation intake occurring as early as March 12 [18].

Figure 4 demonstrates the time-trend of the whereabouts of the 310 subjects of the screening campaign conducted in Kawamata town, Iwaki city and Iitate village at the end of March, 2011. It is noted that no evacuation orders were issued in these municipalities (excluding areas within the $30 \mathrm{~km}$-radius of the FDNPP) before the campaign. Thus, the result suggested that a significant percentage of the persons voluntarily evacuated to other places (partly outside Fukushima Prefecture) and returned at the time of the measurements. It was also found that especailly for those examined in Iite village and Iwaki city, the total number of evacuees reaches to the maximum on March 21. As described later, the thyroid doses received by the 309 subjects were small, so it is difficult to determine if the voluntary evacuation was effective for reducing the doses. This should be further analyzed in addition to the issues addressed in the subjects of the pilot survey. 

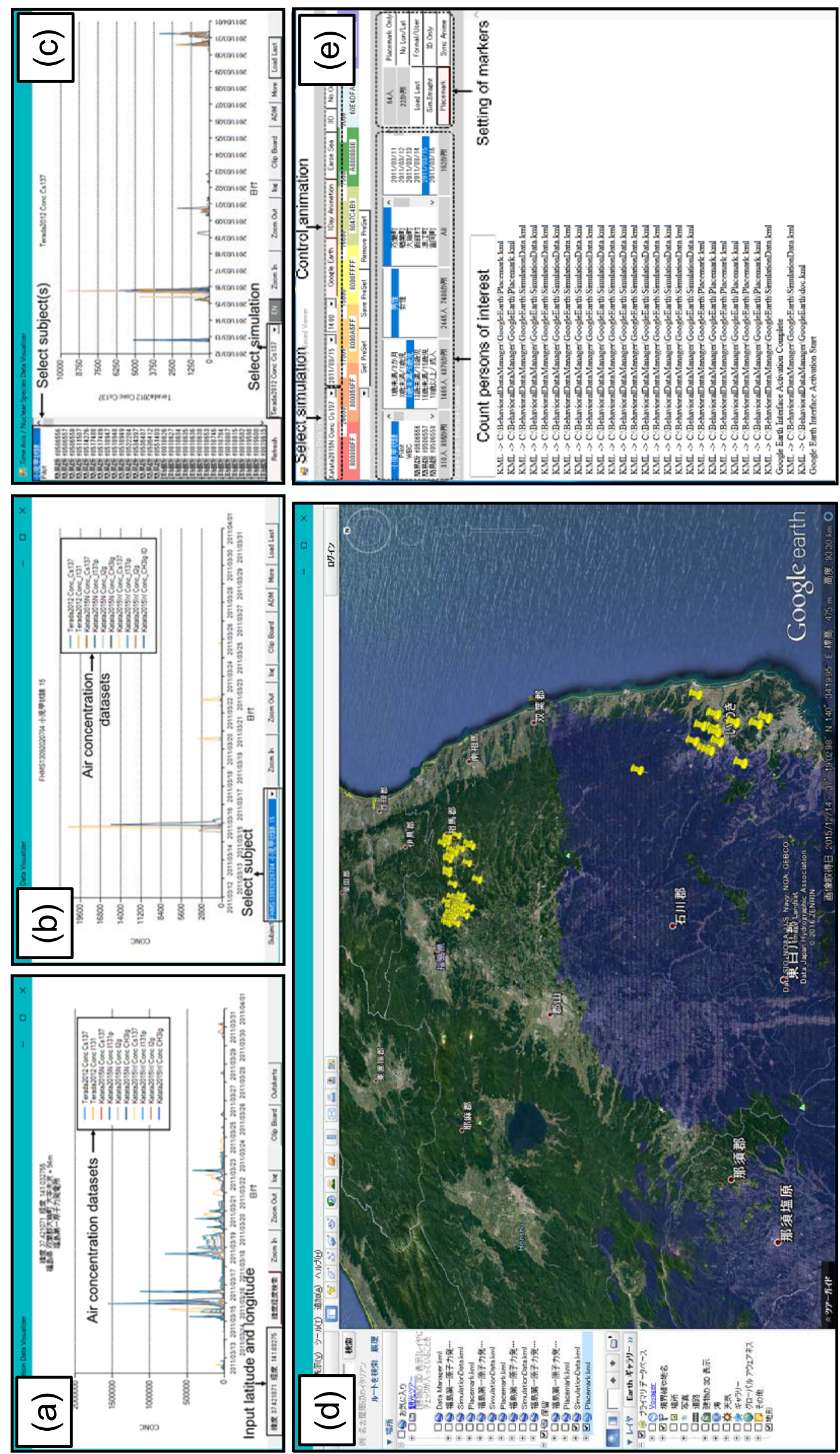

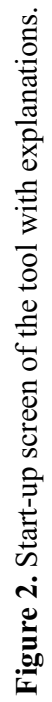

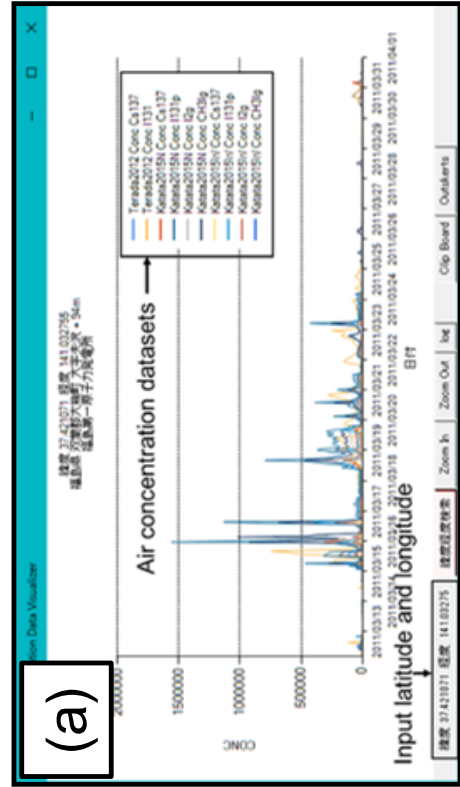




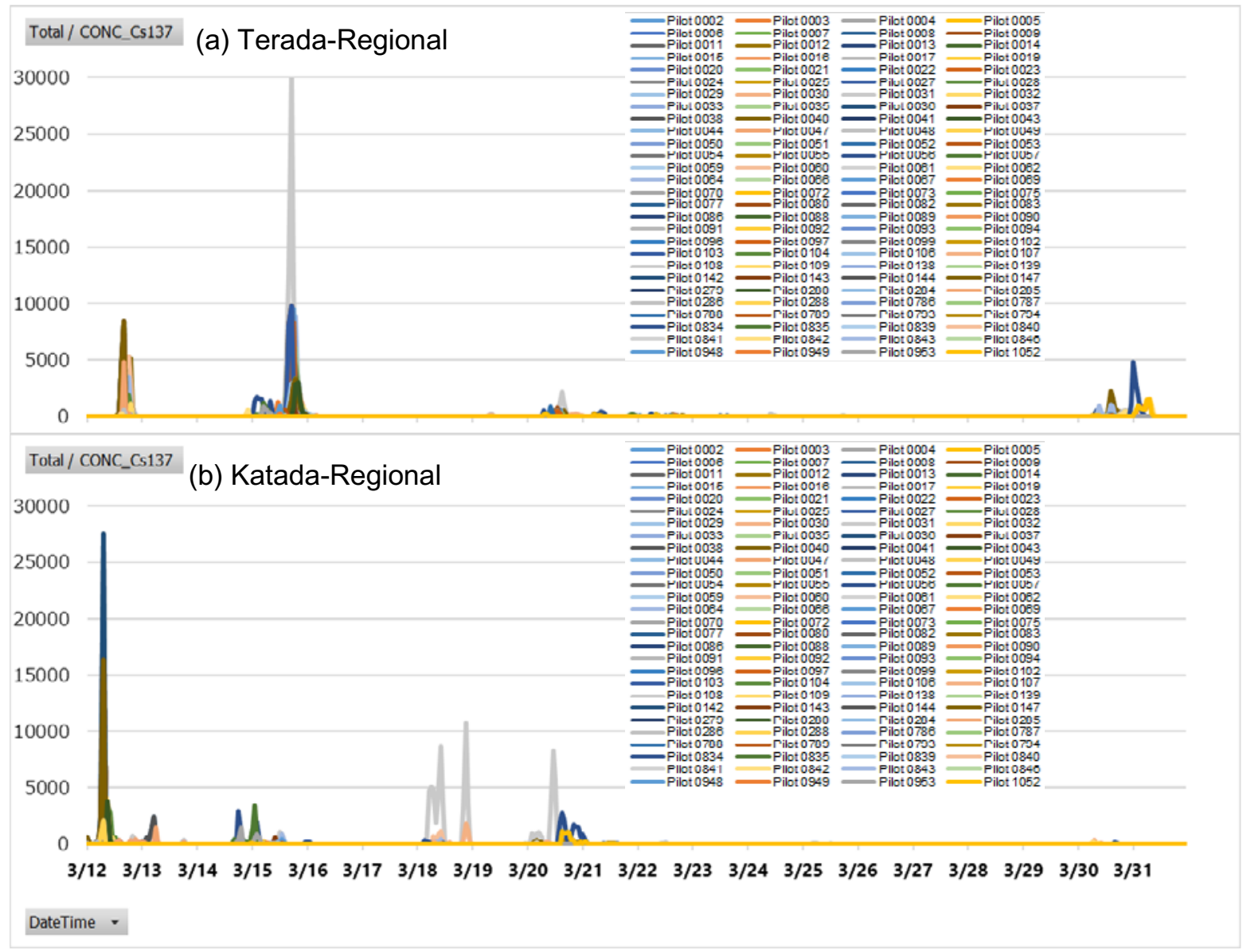

Figure 3. Comparison of ${ }^{137} \mathrm{Cs}$ air concentration between (a) Terada-Regional and (b) Katata-Regional for 112 subjects of the pilot survey.

Time-trend of whereabouts of 310 subjects

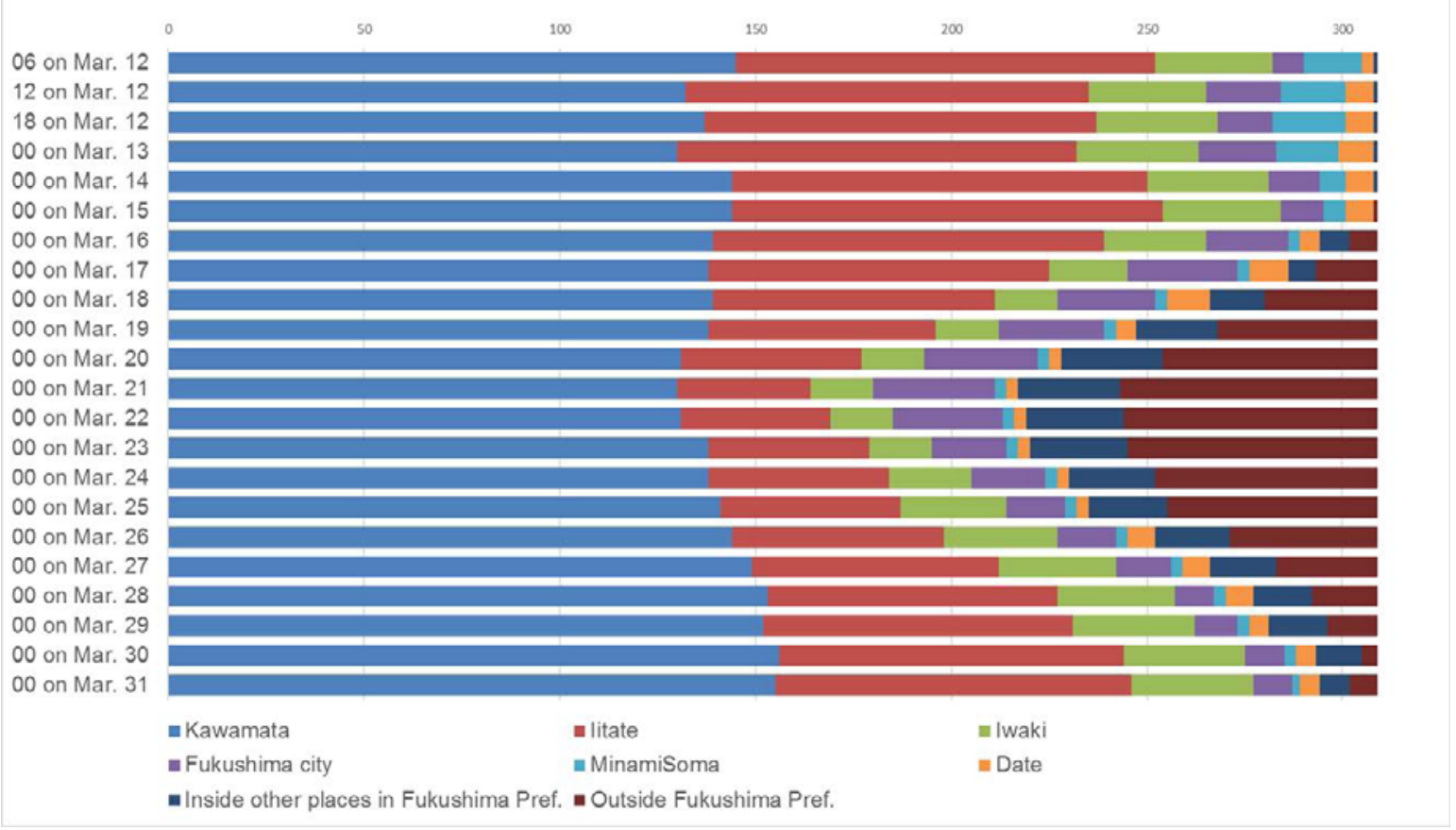

Figure 4. Whereabouts of 310 subjects of the screening campaign. 


\subsection{Comparison between measured and simulated doses}

Figure 5a compares the thyroid equivalent doses $\left({ }^{131} \mathrm{I}\right)$ received by the 309 subjects from the direct measurements (screening campaign) with those determined in the simulation (Terada-Regional). For the latter doses, the rate of indoor to outdoor air concentration, $F$, was set at 0.5 . Figure $5 \mathrm{~b}$ is the same figure, but it compares the direct measurements with another simulation (Katata-Regional). As shown in the figure, the simulations generally tended to give higher doses than the direct measurements, even taking into account the indoor dose reduction. Figure 6 compares the histograms of the thyroid equivalent doses shown above for each municipality where the screening campaign was conducted. The figure demonstrates that the overestimation is more marked in Katata-Regional than in Terada-Regional in the case of Iwaki city and Iitate village, whereas the overestimation in KarataRegional is reduced compared to Terada-Regional in the case of Kawamata town.

Figure $7 \mathrm{a}$ compares the effective doses $\left({ }^{134} \mathrm{Cs}\right.$ and ${ }^{137} \mathrm{Cs}$ ) received by the 112 subjects from the direct measurements (pilot survey) with those determined in the simulation (Terada-Regional). Figure $7 \mathrm{~b}$ is the same figure, but it compares the direct measurements with another simulation (Katata-Regional). The rate of indoor to outdoor air concentration was set at the same level as above. In the case of Terada-Regional, the air concentration of ${ }^{134} \mathrm{Cs}$ was assumed to be the same as that of ${ }^{137} \mathrm{Cs}$ because of the lack of data. Figure 8 compares the histograms of the effective doses determined from the direct measurements with those determined in the simulations. From these figures, it still seems difficult to reproduce the individual doses. Analyses of the persons whose dose were considerably overestimated or underestimated indicated that either the simulations or their personal behavior data were not satisfactorily accurate. Protracted intake until the direct measurements were made can also be considered as one possible reason for the underestimation, if any occurred. On the other hand, the dose distribution from the direct measurements agrees reasonably well with that in the simulations. Further studies are necessary to improve the internal dose estimation based on ATDM simulations and the developed tool would be useful for this future task.

\section{Summary}

Estimation of the early internal dose received by residents in the FDNPP accident based on ATDM simulations is neceaasry because of the shortage of direct measurements of individuals. In the present study, a tool was developed to facilitate this estimation based on the simulations by WSPEEDI-II and the available personal behavior data. The tool generates hourly-averaged air concentration data at the simulation grids nearest to places where the person stayed from the huge datasets of WSPEEDI-II. Using the outputs from the tool, the internal doses received by 421 persons for whom both direct measurement data and personal behavior data were available were calculated and compared with those from the measurements, suggesting a need for further studied to improve the internal dose estimation based on the ATDM simulation. The developed tool would be useful for this future task.

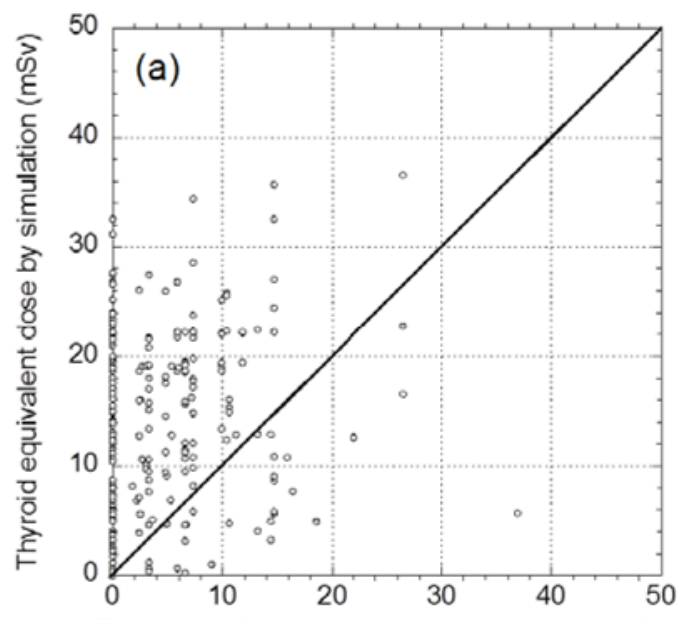

Thyroid equivalent dose by measurement (mSv)

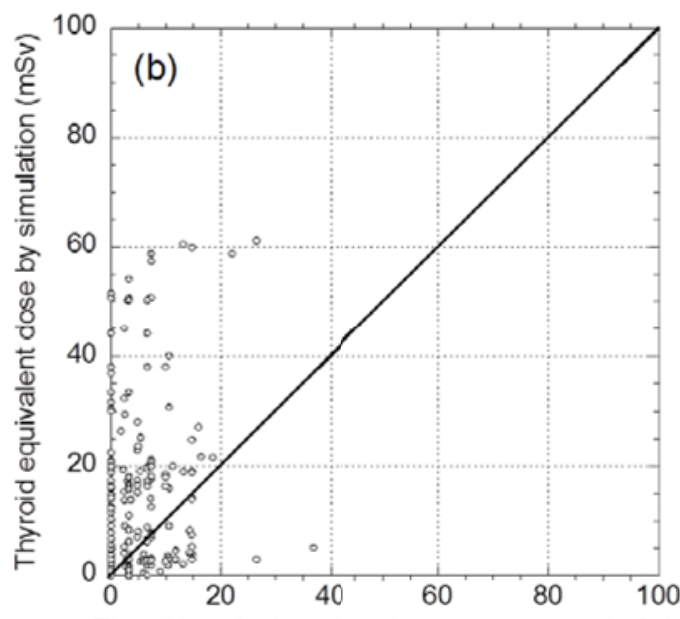

Thyroid equivalent dose by measurement (mSv)

Figure 5. Comparison between direct measurement-based and simulation-based thyroid equaivalent doses $\left({ }^{131} \mathrm{I}\right)$ received by 309 subjects (a: Terada-Regional, b: Katata-Regional). 


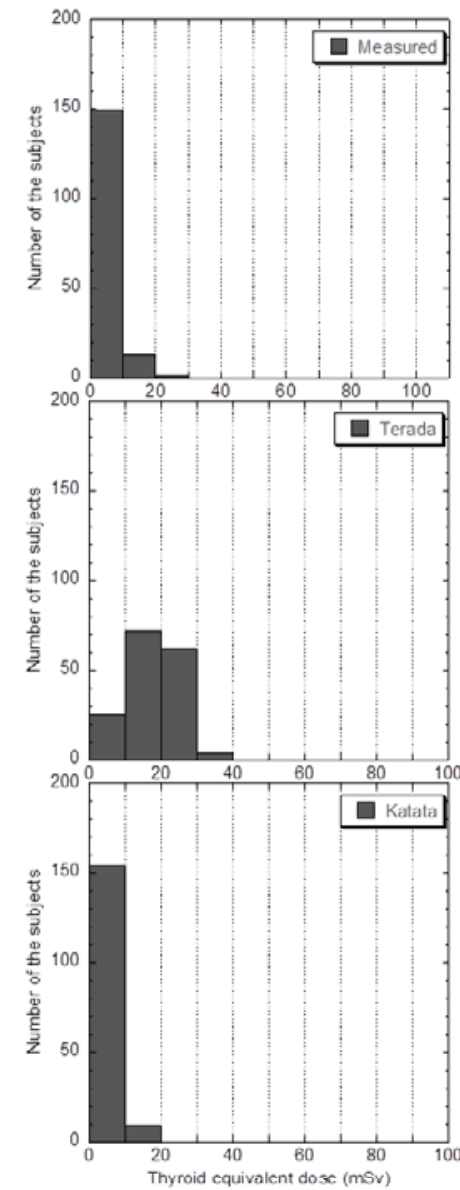

Kawamata

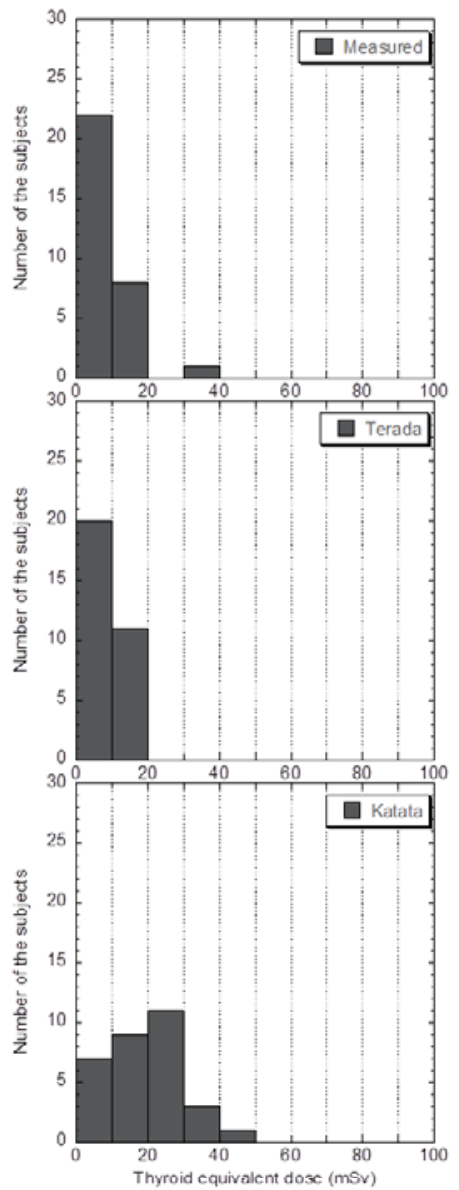

Iwaki

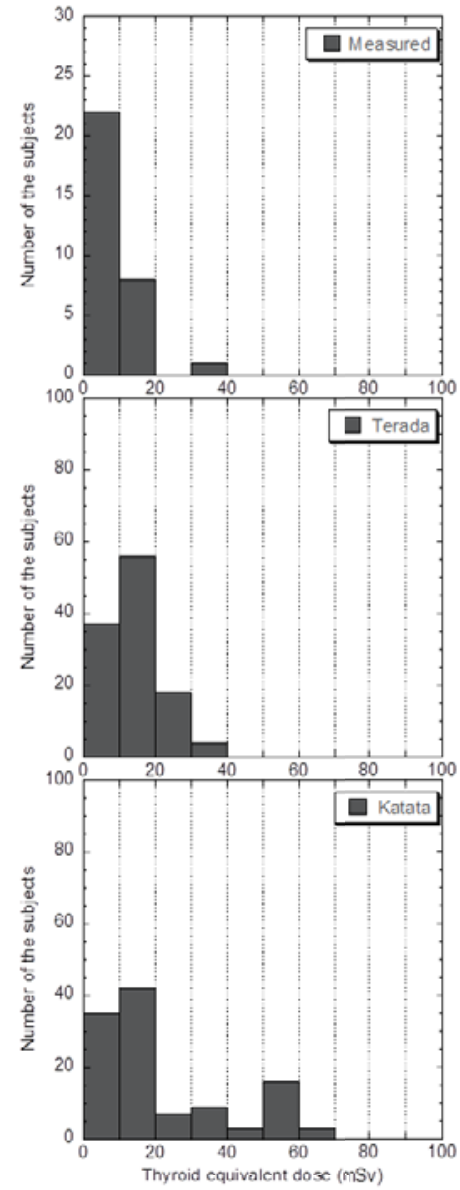

Iitate

Figure 6. Histograms of thyroid equivalent doses (upper row: measured, middle row:Terada-Regional, lower row: Katata-Regional; left column: Kawamata town, middle column: Iwaki city, right column: Iitate village).
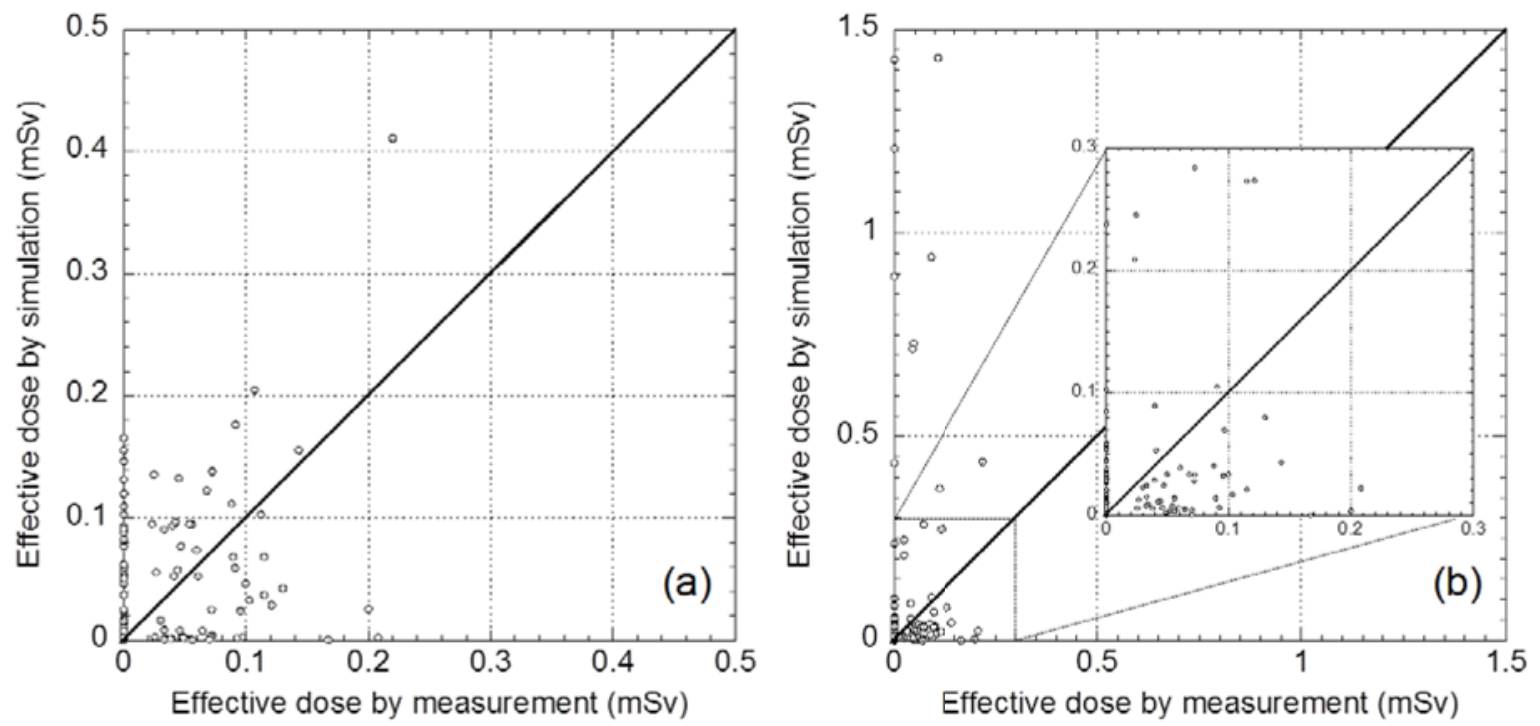

Figure 7. Comparison between direct measurement-based and simulation-based effective doses $\left({ }^{134} \mathrm{Cs}\right.$ and $\left.{ }^{137} \mathrm{Cs}\right)$ received by 112 subjects (a: Terada-Regional, b: Katata-Regional). 

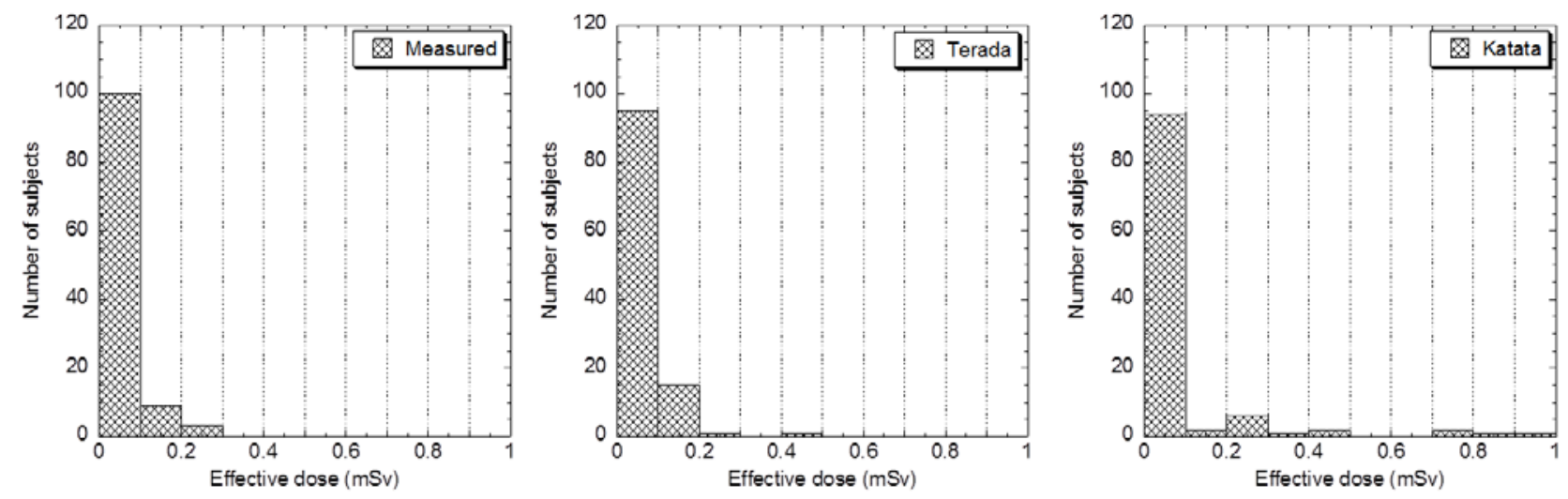

Figure 8. Histograms of effective doses (left: measured, middle: Terada-Regional, right: Katata-Regional).

\section{Acknowledgement}

The authors wish to express their thanks to Dr. Haruyasu Nagai of the Japan Atomic Energy Agency and his colleagues for kindly providing datasets from WSPEEDI-II. This study was conducted as part of the comprehensive study on the dose estimation of resiednts in the Fukushima Daiichi Nuclear Power Plant accident funded by the Ministry of the Environment, Japan (FY. 2014-2016) and also as a collaborative study between the NIRS and Fukushima Medical University.

\section{References}

1. Nuclear Emergency Response Headquarters Government of Japan, Report of Japan Government to the IAEA Ministerial Conference on Nuclear Safety - The accident at TEPCO's Fukushima Nuclear Power Stations June 2011, Available at http://japan.kantei.go.jp/kan/topics/201106/iaea_hou kokusho e.html. Accessed on 24 August 2016.

2. The National Diet of Japan. The official report of the Fukushima Nuclear Accident Independent Investigation Commission. 2012, Available at http://warp.da.ndl.go.jp/info:ndljp/pid/3856371/naiic. go.jp. Accessed on 24 August 2016 (in Japanese).

3. E Kim, O Kurihara, T Suzuki, M Matsumoto, K Fukutsu, Y Yamada, N Sugiura, M Akashi, Proc. of the first NIRS symposium on reconstruction of early internal dose in the TEPCO Fukushima Daiichi nuclear power station accident, NIRS-M-252(2012), Available at http://www.nirs.qst.go.jp/publication/irregular/pdf/nir S m 252.pdf. Accessed on 24 August 2016.

4. S Tokonami, M Hosoda, S Akiba, A Sorimachi, I Kashiwakura and M Balonov, Sci. Rep. 2, 507(2012)

5. N Matsuda, A Kumagai, A Ohtsuru, N Morita, M Miura, M Yoshida, T Kudo, N Takamura and S Yamashita, Radiat. Res. 179, 663 (2013)

6. N Kamada, O Saito, S Endo, A Kimura, K Shizuma, $J$. Environ. Radioact. 110, 84 (2012)
7. $\mathrm{T}$ Momose, $\mathrm{C}$ Takada, $\mathrm{T}$ Nakagawa, K Kanai, O Kurihara, N Tsujimura, Y Ohi, T Murayama, T Suzuki, Y Uezu and S Furuta, Proceedomgs of the first NIRS symposium on reconstruction of early internal dose in the TEPCO Fukushima Daiichi nuclear power station accident, NIRS-M-252 (2012)

8. E Kim, O Kurihara, N Kunishima, T Nakano, K Tani, M Hachiya, T Momose, T Ishikawa, Sh Tokonami, M Hosoda, and M Akashi, Health Phys (to be published)

9. H Terada, H Nagai, A Furuno, $\mathrm{T}$ Kakefuda. T Harayama, M Chino. WSPEEDI 2nd version. J. At. Energy Soc. Jpn. 7, 257(2008). (in Japanese)

10. T Ishikawa, S Yasumura, K Ozasa, K Kobashi, H Yasuda, M Miyazaki, K Akahane, Sh Yonai, A Ohtsuru, A Sakai, R Sakata, K Kamiya and M Abe, Sci. Rep. 5, 12712(2015)

11. H Terada, G Katata, M Chino and H Nagai, J. Environ. Radioact. 112, 141( 2012)

12. G Katata, M Chino, T Kobayashi, H Terada, M Ota, H Nagai, M Kajino, R Draxler, M C Hort, A Malo, T Torii and Y Sanada, Atoms. Chem. Phys. 15, 1029 (2015)

13. United Nation Scientific Committee on the Effect of Atomic Radiation (UNSCEAR). UNSCEAR 2013 report volume 1, Scientific Annex A (2014)

14. E Kim, O Kurihara, N Kunishima, $\mathrm{T}$ Momose, $\mathrm{T}$ Ishikawa, M Akashi, J. Radiat. Res. 57(S1), i118 (2016)

15. O Kurihara, E Kim, K Fukutsu, M Matsumoto, S Soheigh., K Akahane, K Sakai. Radiation Monitoring and Dose Estimation of the Fukushima Nuclear Accident, Takahashi S ed., Speinger Open,177 (2014)

16. International Commission on Radiological Protection, Age-dependent doses to the members of the public from intake of radionuclides: Part 4 inhalation dose coefficients. ICRP Publication 71. Ann. ICRP 25 (3-4), (1995)

17. International Commission on Radiological Protection. Compendium of dose coefficients based on ICRP Publication 60. ICRP Publication 119. Ann. ICRP 41 (Suppl.), (2012)

18. S M Shinkarev, K V Kotenko, E O Granovskaya et al., Radiat. Prot. Dosim. 164, 51(2015) 